\title{
A NEW SPECIES OF VOLLENHOVIA (HYMENOPTERA, FORMICIDAE) FROM INDIA WITH KEY TO KNOWN INDIAN SPECIES
}

\author{
H. Bharti', R. Kumar ${ }^{2}$ \\ Department of Zoology \& Environmental Sciences, Punjabi University, \\ Patiala, Punjab - 147002, India \\ E-mail: ${ }^{1}$ himenderbharti@gmail.com; ${ }^{2}$ rakeshsharmassm@gmail.com
}

\begin{abstract}
A New Species of Vollenhovia (Hymenoptera, Formicidae) From India with Key to Known Indian Species. Bharti H., Kumar R. - Vollenhovia gastropunctata Bharti et Kumar, sp. n. (Hymenoptera, Formicidae) is described and illustrated based on the worker caste from India. A key to the Indian species of Vollenhovia Mayr, 1865 is provided.
\end{abstract}

Key words: Hymenoptera, Formicidae, ants, Vollenhovia, new species, India, key.

Новый вид Vollenhovia (Hуmenoptera, Formicidae) из Индии, с таблицей для определения известных индийских видов. Бхарти Х., Кумар Р. - Иллюстрированное описание Vollenhovia gastropunctata Bharti et Kumar, sp. n. (Hymenoptera, Formicidae) по рабочим особям из Индии. Составлена таблица для определения видов рода Vollenhovia Mayr, 1865, обитающих в Индии.

Кл ючевы е слова: Hуmenoptera, Formicidae, муравьи, Vollenhovia, новый вид, Индия, таблица для определения.

\section{Introduction}

The genus Vollenhovia Mayr, 1865 belongs to the tribe Stenammini of the subfamily Myrmicinae. These are small to moderate sized ants; some of them are social parasites. By far, it was represented by 60 species and 18 subspecies worldwide (Bolton, 2011) and one species from India (Bharti, 2011). Vollenhovia gastropunctata Bharti et Kumar sp. n. is quite distinct from already known species. A key to the Indian species of Vollenhovia is provided.

\section{Materials and methods}

The material was collected from Mangifera indica L. (Anacardiaceae) tree. The digital images were prepared on Nikon SMZ-1500 stereo zoom microscope using Auto-Montage software.

\section{Measurements and Indices:}

EL - Eye Length. Maximum length of eye measured in same view as HL.

GL - Gaster Length. Maximum length of gaster in lateral view from the anteriormost point of first gastral segment to the posterior most point (excluding sting).

HL - Head Length. The length of the head proper, excluding the mandibles, measured in a straight line from the mid-point of the anterior clypeal margin to the midpoint of the occipital margin, in full face view.

HW - Head Width. The maximum width of the head in full face view (measured including the eyes).

ML - Mesosoma Length. The diagonal length of the mesosoma in profile from the point at which the pronotum meets the cervical shield to the posterior extension of the propodeal lobes.

PTH - Petiole Height. Maximum height of petiole in profile.

PTL - Petiole Length. Maximum length of petiole in dorsal view.

PTW - Petiole Width. Maximum width of petiole in dorsal view.

PPTH - Postpetiole Height. Maximum height of postpetiole in profile.

PPTL - Postpetiole Length. Maximum length of postpetiole in dorsal view.

PPTW - Postpetiole Width. Maximum width of postpetiole in dorsal view.

PRNW - Pronotal Width. The maximum width of the pronotum in dorsal view.

SL - Scape Length. The maximum straight line length of the antennal scape excluding the basal constriction or neck close to the condylar bulb. 
TL - Total Length. HL + ML + PTL + PPTL + GL.

CI - Cephalic Index. (HW/HL) $\times 100$

SI - Scape Index. $(\mathrm{SL} / \mathrm{HW}) \times 100$

Vollenhovia gastropunctata Bharti et Kumar, sp. n. (fig. 1-3)

M a terial. Holotype worker: India, Himachal Pradesh, Andretta $\left(32.036638^{\circ} \mathrm{N}, 76.566532^{\circ} \mathrm{E}\right), 940 \mathrm{~m}$, 15.06.2010, hand picking (Kumar). Holotype deposited in Punjabi University Patiala Ant Collection (PUPAC), Patiala, India. Paratype. 1 worker, same data as holotype.

Description. Holotype worker. HL 0.56, HW 0.49, SL 0.33, EL 0.12, ML 0.73, PRNW 0.36, PTL 0.24, PTW 0.18, PTH 0.23, PPTL 0.24, PPTW 0.20, PPTH 0.19, GL 0.76, TL 2.53, CI 87.50, SI 67.35.

Paratype worker. HL 0.56, HW 0.49, SL 0.33, EL 0.12, ML 0.75, PRNW 0.36, PTL 0.23, PTW 0.18, PTH 0.23, PPTL 0.24, PPTW 0.20, PPTH 0.19, GL 0.76, TL 2.54, CI 87.50, SI $67.35(n=1)$.

Head slightly longer than wide, slightly broader posteriorly than in front, with subparallel sides, occipital margin concave; mandibles with 7 teeth including well developed basalmost tooth, masticatory margin of mandibles with large apical and preapical teeth followed by 5 teeth of equal size; anterior clypeal margin concave; antennae 12-segmented with distinct 3 -segmented club; scape $0.59 \times$ as long as head; eyes large, placed at midlength of the head.

Mesosoma nearly flat (seen in profile) and sloping toward propodeal declivity, promesonotal suture and metanotal groove indistinct; posterodorsal corners of propodeum weakly angulated, without distinct teeth.

Petiole convex, longer than wide, posterodorsal margin angulate, subpetiolar process $(0.07 \mathrm{~mm}$ long and $0.05 \mathrm{~mm}$ high in profile $)$ well developed and rectangular in shape; postpetiole convex, slightly longer than wide; gaster elliptical.
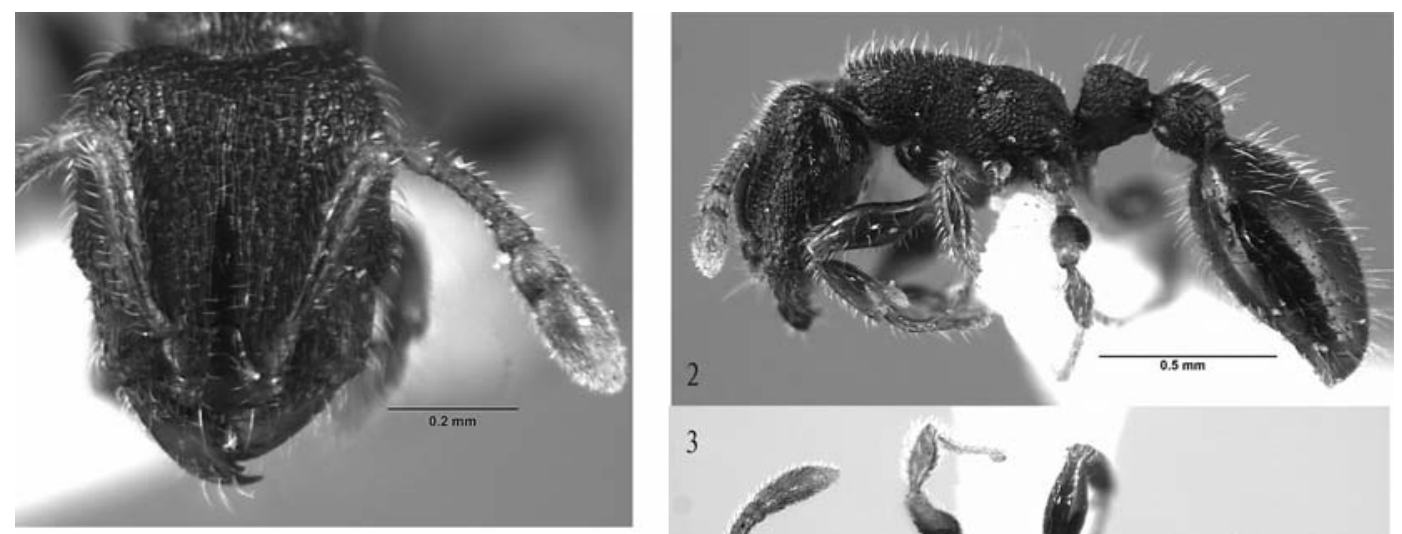

1

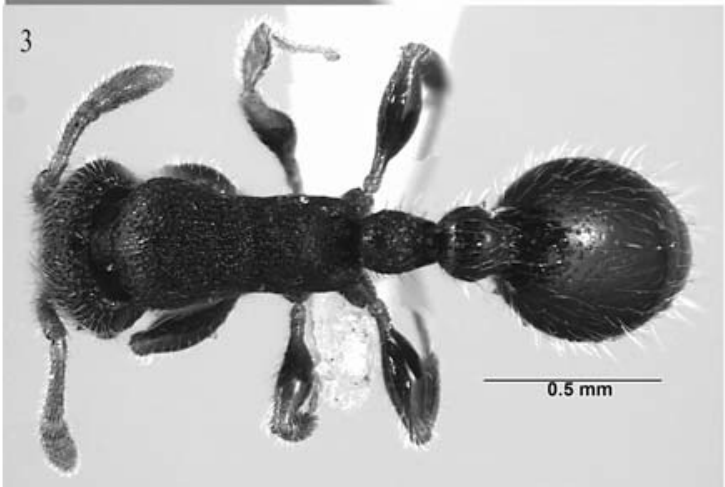

Fig. 1-3. Vollenhovia gastropunctata sp. n., worker: $1-$ head in full-face view; 2 - lateral view; $3-$ dorsal view.

Рис. 1-3. Vollenhovia gastropunctata sp. n., рабочий: 1 - голова, общий вид; 2 - вид сбоку; 3 - вид сверху. 
Sculpture. Head shagreened, with large coarse punctures of $0.02 \mathrm{~mm}$ diameter and longitudinal unsculptured central band; mandibles shiny, with scattered punctures; clypeus smooth with two longitudinal carinae, divergent toward its anterior end; promesonotum longitudinally rugose, with punctures; dorsum of propodeum and its declivity minutely punctured (0.01 mm diameter); sides of mesosoma coarsely punctuated; petiole and postpetiole reticulate except the anterior face of petiolar node and mid dorsum of postpetiole, which are smooth; 1st gastral tergite with scattered punctures, rest smooth and shiny.

Colour and pilosity. Body blackish brown; mandibles, antennae, legs and subpetiolar process yellowish brown. Whole body covered with abundant long, suberect, whitish hairs.

Distribution and habitat. This species seems to be uncommon, as it was recorded only from one habitat during intensive survey of North-West Shivalik. The species was collected from a semiarid type of environment and seems arboreal, as it was collected from a mango tree.

Etymology. The specific epithet refers to the punctures on gaster.

Differential diagnosis. Vollenhovia gastropunctata sp. n. can be distinguished from its other congeners by the following combination of characters: mandibles punctured, with 7 teeth, antennae 12-segmented, whole of the promesonotum sculptured, large size of subpetiolar process, absence of propodeal teeth, an unsculptured longitudinal band on head, clypeus with two longitudinal carinae, divergent toward its anterior end, and metanotal groove indistinct.

However, this species somewhat resembles $V$. benzai Terayama and Kinomura, 1997 and $V$. amamiana Terayama and Kinomura, 1997. The new species can be separated from them by the following characters: mandibles with prominent, well developed basalmost tooth, promesonotum sloping backward, larger subpetiolar process $(0.05 \mathrm{~mm}$ high), gaster with scattered punctures on 1st tergite (rest shiny), total length 2.53-2.54 mm and body colour blackish brown (in $V$. benzai, basal tooth of mandible minute, promesonotum straight, subpetiolar process small $(0.03 \mathrm{~mm}$ in height $)$, gaster without punctures, subopaque, body colour reddish brown and total length $2.00-2.20 \mathrm{~mm}$ ). V. gastropunctata sp. n. can be easily separated from $V$. amamiana by the absence of large brown spot on frons, subpetiolar process longer than its height $(0.07 \mathrm{~mm}$ in length and $0.05 \mathrm{~mm}$ in height) and body colour blackish brown while in $V$. amamiana frons with a large brown spot, subpetiolar process higher than long $(0.08 \mathrm{~mm}$ high $)$ and body colour reddish brown.

Key to the Indian species of the genus Vollenhovia based on worker caste

Таблица для определения видов рода Vollenhovia, обитающих в Индии, по рабочим муравьям

1. Mesosoma smooth and shiny, with a few delicate scattered punctures anteriorly; mandibles with 6 teeth; body length $\leq 2 \mathrm{~mm}$. V. oblonga (F. Smith) (subspecies laevithorax Emery, large in size; worker 3.75-4.0 mm)

- $\quad$ Mesosoma punctured; mandibles with 7 teeth; body length $\geq 2.5 \mathrm{~mm}$. V. gastropunctata.

Financial assistance rendered by Ministry of Environment and Forests (Grant No. 14/10/2007-ERS/RE), Govt. of India, New Delhi is gratefully acknowledged.

\section{References}

Bharti H. List of Indian Ants (Hymenoptera: Formicidae) // Halteres. - 2011. - 3. - P. 79-87.

Bolton B. Bolton's Synopsis and Catalogue 2011. Available from: http: // gap. entclub. org/ "Version: 1 July, 2011". Mayr G. Reise der Österreichischen Fregatte Novara um die Erde in den Jahren 1857, 1858, 1859, unter den befehlen des Commodore B. von Wüllerstorf-Urbair // Zoologischer Theil: Formicidae. - Vienna, 1865. P. 119.

Terayama M., Kinomura K. Taxonomic studies of Japanese Formicidae, part 3. Genus Vollenhovia Mayr // Nature and Human Activities. - 1997. - 2. - P. 1-8.

Received 29 December 2012

Accepted 21 March 2013 